University of Nebraska - Lincoln

DigitalCommons@University of Nebraska - Lincoln

Architecture Program: Faculty Scholarly and

Creative Activity

Architecture Program

1998

\title{
A Critical Review of Design and Use of Field Tent Shelters in Polar Regions
}

Xiaoying Winston Yan

University of Nebraska - Lincoln

Marijane E. England

University of Nebraska - Lincoln

Karl C. Kuivinen

University of Nebraska - Lincoln

James J. Potter

University of Nebraska - Lincoln, jpotter2@unl.edu

Nathan S. Krug

University of Nebraska - Lincoln, nkrug1@unl.edu

Follow this and additional works at: https://digitalcommons.unl.edu/arch_facultyschol

Part of the Architecture Commons

Yan, Xiaoying Winston; England, Marijane E.; Kuivinen, Karl C.; Potter, James J.; and Krug, Nathan S., "A Critical Review of Design and Use of Field Tent Shelters in Polar Regions" (1998). Architecture Program: Faculty Scholarly and Creative Activity. 2.

https://digitalcommons.unl.edu/arch_facultyschol/2

This Article is brought to you for free and open access by the Architecture Program at DigitalCommons@University of Nebraska - Lincoln. It has been accepted for inclusion in Architecture Program: Faculty Scholarly and Creative Activity by an authorized administrator of DigitalCommons@University of Nebraska - Lincoln. 


\section{A critical review of design and use of field tent shelters in polar regions \\ Xiaoying Winston Yan \\ Department of Architecture, University of Nebraska-Lincoln, 232 Arch Hall, Lincoln, NE 68588-0107, USA}

Marijane E. England and Karl C. Kuivinen

Polar Ice Coring Office, University of Nebraska-Lincoln, 105 Whittier Building, Lincoln, NE 68588-0850, USA

James J. Potter and Nathan S. Krug

Department of Architecture, University of Nebraska-Lincoln, 232 Arch Hall, Lincoln, NE 68588-0107, USA

\section{Received March 1997}

ABSTRACT. Polar research teams often spend extended periods of time away from base stations, living and working in remote field camps of portable tents. This article reports results of a survey study conducted in 1996 of polar researchers from the United States. The study was about the design and use of portable field tents being deployed in polar areas with regard to safety, health, and well-being from the user's perspective. Preliminary analysis indicates that there existed a number of areas in design and use of the shelters that contributed to concerns of safety, health, and well-being among a considerable number of tent users. The article concludes with suggestions for designing and manufacturing portable field tents.

\section{Contents}

Introduction

Literature review

Method and procedure

Results and discussions

Conclusion and limitations

Acknowledgements

References

114

115

120

122

122

\section{Introduction}

When scientists and their support teams work away from base stations in polar and sub-polar areas, they often depend on temporary, portable field tent shelters for protection from the harsh environment. If the polar and subpolar climatic and social conditions pose a serious challenge to people living in permanent base stations, the challenge becomes even greater for those who have to stay in remote field tents for an extended period. Performance of the tent is of vital importance not only for weather protection, but also for the social and psychological wellbeing of its users.

To date, little comprehensive research has been conducted about the impact on the users of remote field tents deployed in polar regions. Since 1993, a team of investigators from the College of Architecture and the Polar Ice Coring Office (PICO) at the University of NebraskaLincoln has been conducting a study on field tents. The study focuses on the following research questions:

1. To what extent do the design and use of the tents affect the safety, health, and sense of well-being of users?

2. Do people using different types of tents experience different problems, and if so, to what extent?

3. What factors are more important and contribute more significantly than the others to safety, health, and well-being of users?

4. What performance criteria for the field tents are necessary to specify for manufacture that will not only provide survival protection, but also promote health and well-being for users?

This article reports preliminary findings of the study that have direct implications for design and use of the field tents.

\section{Literature review}

An extensive literature review pointed out many issues related to the impact on human beings of the harsh polar and sub-polar climatic and social conditions, and revealed some limitations in previous studies of the design and use of portable field tents.

While there is substantial literature available concerning the design and construction of tents deployed in polar regions, most of the existing literature describes and evaluates the large, permanent and semi-permanent structures designed for field teams spending extended periods in a single location (Brier 1969; Johnson 1970; Alexander 1972; Floyd 1974; Richter 1979; Flanders 1980; Oakley 1986; Antarctic Support Associates 1991; Pearson 1992). However, studies and literature on the small, portable field structures designed for up to four persons are much less available. Furthermore, the available literature relating to portable tents is now 10-20 years old. There appears to have been little written since the development and widespread adoption of new light-weight synthetic fabrics in tent design.

Past research on field tents has focused on either the performance expectations for materials (Flanders 1982; Hutcheon and Handegord 1983), energy conservation (Ledbetter 1976), utility requirements such as water or waste disposal (Mellor 1969), or impact of human activi- 
Table 1. Experience of survey respondents.

\begin{tabular}{|l|c|c|c|}
\hline Research sites & $\begin{array}{c}\text { Number of } \\
\text { respondents }\end{array}$ & $\begin{array}{c}\text { Number of } \\
\text { times deployed }\end{array}$ & $\begin{array}{c}\text { Number of } \\
\text { weeks of deployment }\end{array}$ \\
\hline Antarctica & 81 & $1-26$ & $1-180$ \\
Greenland & 34 & $1-10$ & $1-70$ \\
Alaska & 33 & $1-60$ & $1-260$ \\
Others (Siberia and Iceland) & 11 & $1-6$ & $1-20$ \\
\hline
\end{tabular}

ties on the environment in the polar regions (Harris 1991; Osherenko 1992). Little research appears to have been done on the overall performance of the tents from the users' points of view.

Although there have been studies of field tents from the psychological and physiological perspectives of their users, these studies have tended to focus more on human adaptation to the harsh conditions and the isolated and confined environments (ICEs) (Suedfeld 1991). Some studies attempted to determine the characteristics of a person able to withstand the pressures of the harsh and confined environment (Gunderson 1974), to find out different coping mechanisms, or to help facilitate the adaptation (Natani and Shurley 1979; Carrere 1990; Mocellin and Suedfeld 1991; Cravalho 1994; Offen 1994). From an environmental behavioral point of view, adaptation to an environment is only one of the two essential human interactions with its environment. The influence or impact of the environment on people is the other. As some early studies suggested, while humans are able to adapt to the harshest of conditions, psychological deterioration tends to occur when there is a long period of sub-acute frustration, privation, and confinement (Suedfeld 1987). The built environment often played a major role in an individual's well-being under ICE conditions (Carrere and Evans 1994). For instance, ICEs tended to make people highlight the importance of privacy and personal territory, and to heighten the need for flexibility and novelty and the freedom to personalize the environment.

The last, but not the least important, limitation of the previous studies resides in research methodology. While each year several hundred people from the US went to Antarctica, of which a large percentage used field tents, there is relatively little to be found in the literature that took a 'post-occupancy evaluation' (POE) approach to evaluate the various types of portable tents from a user perspective. As a method of built environmental research, POE has proven to be effective in advancing knowledge about the built environment and providing feedback for design and use of the built environment (Marans and Spreckelmeyer 1981; Preiser and others 1988). Portable field tents, although small, constitute an important part of the built environment for their users. A study of design and use of the tents based on experience of their users is essential in order to make the tents not only a protection for survival, but an environment maintaining and promoting wellbeing of users.

\section{Method and procedure}

The data collection of the study involved two steps. First, a telephone interview of selected polar researchers was conducted in September and October 1995. The interview addressed issues concerning both performance of the tents and psychological well-being of users as affected by the design and use of the tents. Second, based on findings from the telephone interviews, a self-administered, mail-in survey questionnaire was developed. The survey was carried out from January through February 1996.

Utilizing information from the Office of Polar Programs at the National Science Foundation (NSF), and PICO at the University of Nebraska-Lincoln, a pool of potential study participants was generated. Some were research scientists, while others were support technicians. All had traveled to the polar regions and used field tents in the recent years. From the pool, a sample of 30 respondents was selected for the interviews, and more than 200 were identified for the questionnaire survey. In total, 16 people were interviewed by telephone and 105 have returned the survey questionnaire.

Table 1 presents the statistics of the study respondents with regard to their experience in the polar regions. Many went to more than one area for several times during the last 10 years. Some had accumulated experience of as many as 260 weeks. The extensive experience of the respondents helps assure validity of the study.

The questionnaire was composed of five sections: general background information about respondents' experience with different polar and sub-polar areas and the types of tents used; climatic and weather conditions the respondents encountered while in those regions; evaluations of physical properties and features of the field tent; behavioral information on use of the field tent; and the influence of design and use of the tents on the well-being of users. More than 150 questions were included in the questionnaire, of which a majority used a structured, closeended format. A pre-test of the survey questionnaire was conducted on the campus of the University of NebraskaLincoln with both scientists and support personnel who had gone to the polar and sub-polar regions many times and were experienced users of the various tents under investigation. Input from the pre-test was subsequently integrated into the final version of the questionnaire.

Information about user well-being was gathered using data-collection techniques based on several early environmental psychological studies (Byrne and others 1963; Derogatis and others 1974; Mackay and others 1978; Leon 1991; Ursin and others 1991). The studies all used a selfdescriptive questionnaire as the instrument to measure psychological well-being, including such terms as mood, stress, depression, and anxiety. While the previous re- 
search addressed these issues in great depth and detail from a clinical psychological perspective, this study used part of their measurements in a modest way. Only those items that were relevant to, and potentially had implications for, design and use of the field tent were used in the questionnaire.

In addition to the data of user well-being, the questionnaire included a detailed inquiry of many design issues, ranging from tent sizes, to door types, materials, colors, insulation, and ability for personalization inside tents. This detailed information about the tent was included for analyzing possible relations between the design and the well-being of users, and eventually helping establish performance criteria of tents for manufacturing and outfitting.

The data analysis took a comparative approach that grouped the tents into three clusters: the small, commonly used Scott-type or ArcticOven type tents (abbreviated as S\&A tents hereafter); all other small tents, such as Dome, North Face, Weatherport tents and miscellaneous others (abbreviated as D\&N tents hereafter); and the relatively large tent shelters of the Jamesway and Polarhaven types for multiple occupants (abbreviated as J\&P tents hereafter).

There were two reasons to single out the S\&A tents from the other small tents: their abundant use in field camps, and the number of respondents of S\&A tent users (36 respondents, or $34 \%$ of the total respondents), which was sufficient to make one group for comparative statistical analysis. The inclusion of the relatively large and semipermanent shelters like the Jamesway in this study was compelled by two considerations: their abundant use in field camps, and their distinctly different design and use features from the smaller ones. This enabled the study to determine differences in evaluations between the small and the large tents with regard to design and user safety, health, and well-being.

\section{Results and discussions}

Preliminary analysis of the data indicates that while evaluations of the tents were generally positive, levels of user satisfaction varied with different tents. Figure 1 shows overall evaluations of various types of the field tents based on the respondents' overall experience through the years. It should be noted that many respondents used more than one type of field tent. The evaluation was measured on a four-point scale with one being the most negative and four the most positive.

Further analysis of various aspects of design and use of the tents tends to suggest that there exist many areas in which users experienced problems, and that future improvements are needed. The following discussion provides a critical review of those issues and problems.

\section{Safety and health}

The survey data suggest that the tents seemed to have performed well in providing protection from the extremely harsh climatic conditions. Few respondents ever experienced serious weather-related problems with their tents, and the materials and structures of the tents were durable and capable of withstanding high winds and blowing snow. As a result, the respondents showed little concern about their safety even when they were confined to the tents due to severe weather. For instance, only about $6 \%$ of the respondents of S\&A tent users and $19 \%$ of D\&N tent users indicated they were concerned about their safety when weather conditions were severe (Fig. 2). However, when asked whether their tents had ever failed to provide protection due to harsh weather conditions, S\&A and $\mathrm{D} \& \mathrm{~N}$ tent users indicated rather significant differences. While only $9.5 \%$ of the respondents of S\&A tent users experienced tent failures at least once, about $44 \%$ of D\&N tent users did. Apparently, the S\&A tents have a much better capability of resisting harsh weather than the other types of small tents. The failures included bent poles, fabric rips, leaking, poor ventilation, snow drifting, frosting inside, broken braces caused by snow build-up, and broken doors. Some respondents had their tents completely destroyed by high winds.

While much of the attention regarding human safety was generally given to that of harsh weather, the data indicate that there was a concern for fire safety among a considerable number of users. For instance, about onefourth $(23 \%)$ of S\&A tent users, $43 \%$ of D\&N tent users, and $35 \%$ of $\mathrm{J} \& \mathrm{P}$ users reported that, to a varying degree, they did not feel that their tents were safe from fire (Fig. 3). The feeling about fire safety seemed to be more psychological than real, for only one fire accident was reported by respondents. However, a concern for fire safety in the minds of users would nevertheless adversely affect their well-being.

Fire safety became a greater concern among those who used various types of heating systems and/or did extensive cooking inside their tents. About $56 \%$ of the respondents who used auxiliary heating systems extensively and $50 \%$ of those who cooked almost daily inside tents indicated they were concerned about fire safety (Fig. 4). In fact, some respondents mentioned that they always kept a fire extinguisher and sharp knife handy in case of fire emergency. The concern is worth noting because using an auxiliary heating system and cooking inside tent shelters were not uncommon. The data of this study show that a little more than one-third (38\%) of the respondents used an auxiliary heating system and $35 \%$ of them cooked almost daily inside their tents. A majority of them (70\%) used gas stoves for cooking.

One finding related to safety and health is about oxygen depletion due to cooking inside tent shelters. Among those who cooked extensively, about $28 \%$ of tent users said they were concerned about oxygen depletion (Fig. 5).

There also existed a variation in user evaluations of such indoor environmental quality factors as indoor temperature, humidity, air quality, noise conditions, and moisture build-up (Table 2). While the data of this study indicate that a majority of the respondents seemed to have positive evaluations with regard to those factors, the number of those whose evaluations were negative is not at all inconsiderable. On one hand, about $21 \%$ of S\&A tent 
$\underline{\text { S\&A tents }}$ (percentage distributions)

Scott, mean=3.0, $\mathrm{n}=65$ (left bar) $\quad$ ArcticOven, mean $=3.3, \mathrm{n}=17$

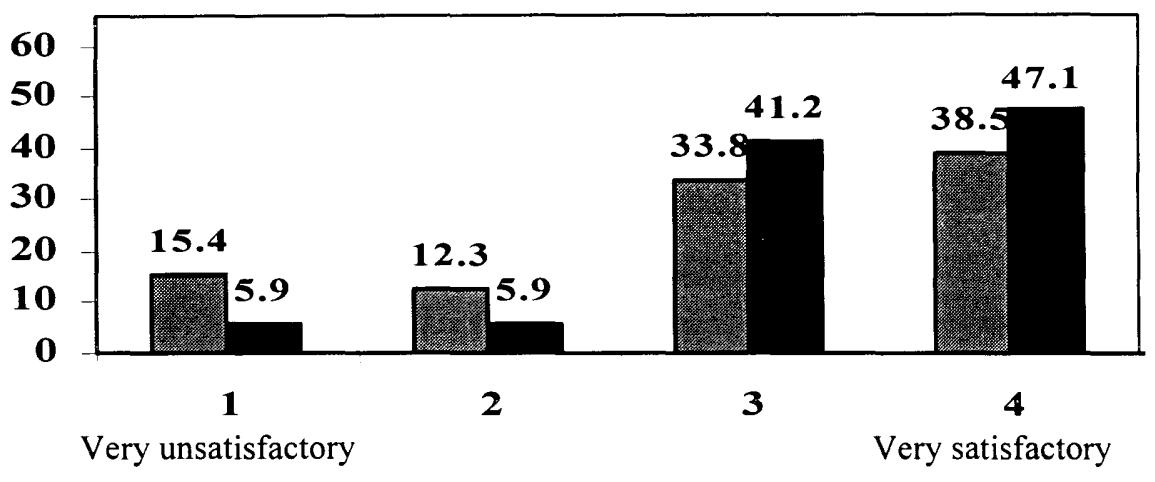

D\&N tents (percentage distributions)

Dome tents, mean=2.9, $n=17$ (1st from left) $\quad$ North Face VE25, mean=2.9, $n=27$ (2nd)

Other North Face VE, mean=3.1, n=14 (3rd) All other small tents, mean=3.2, $n=26$ (4th)

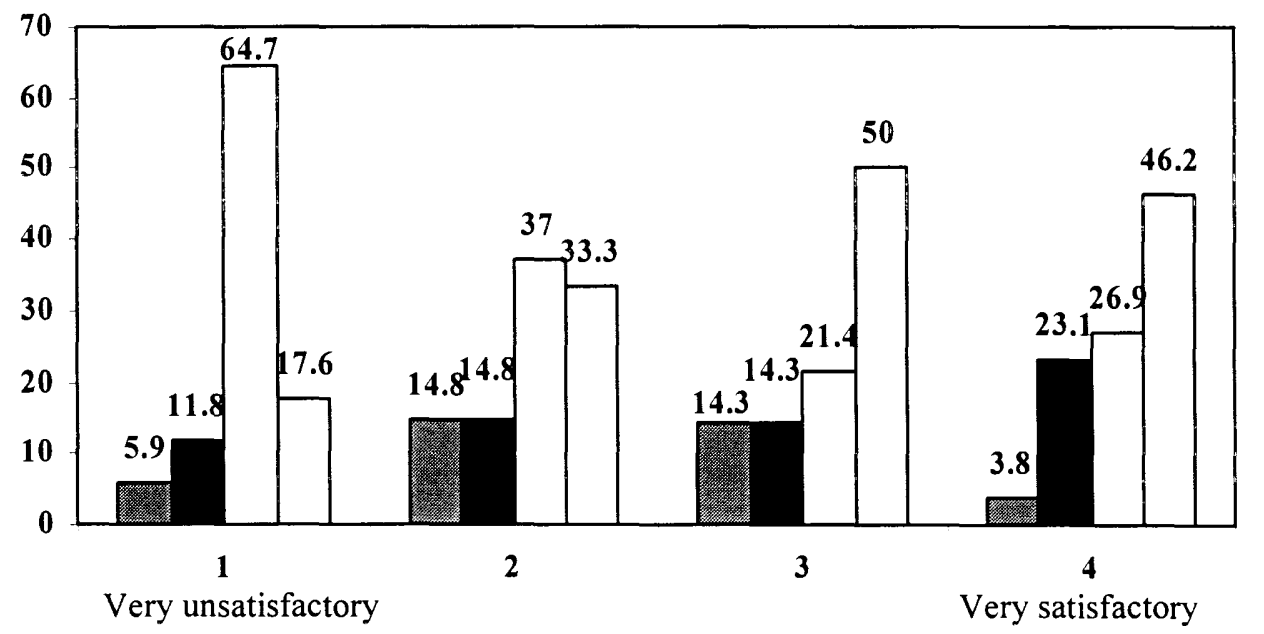

$\underline{\text { J\&P tents }}$ (percentage distributions)

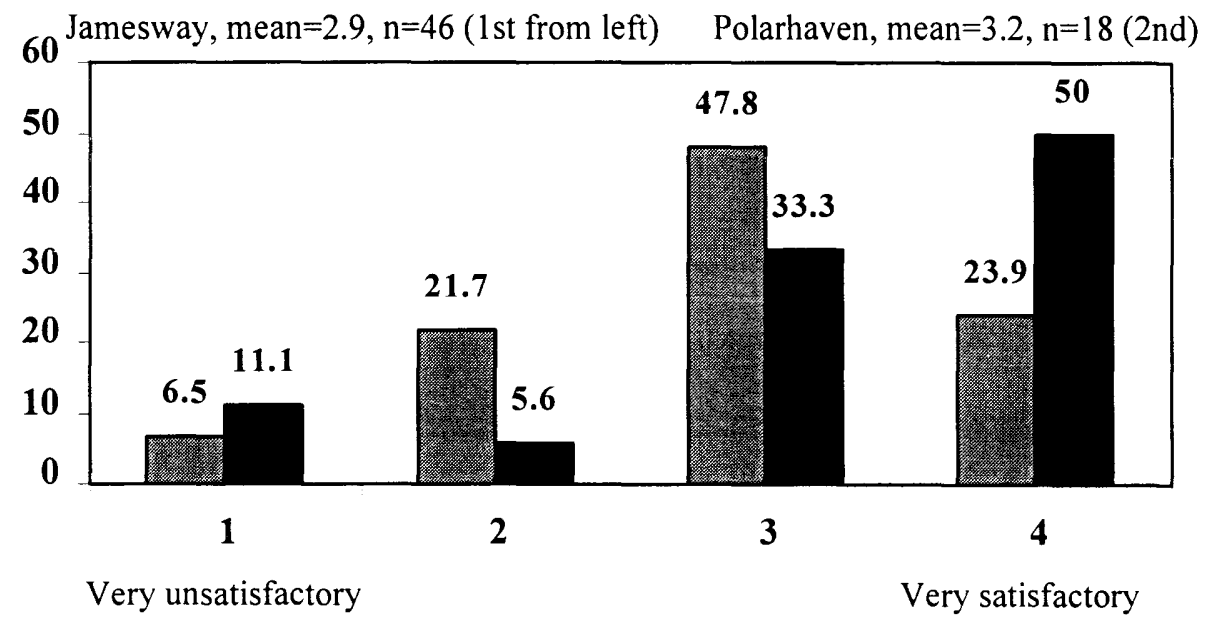

Fig. 1. Overall evaluations of various types of tents. Question: 'Please tell us your overall evaluation of the tents.'

those who felt it was too cold inside tents increased among users of all three groups: $21 \%$ for S\&A tents, $29 \%$ for D\&N tents, and $28 \%$ for $\mathrm{J} \& \mathrm{P}$ tents. The problematic experience with indoor temperature brings about a design issue. To address great temperature variation and fluctuation between day and night, and from subpolar to polar regions, different tent designs are needed. For instance, adding operable windows and using different fabric materials may be highly desirable in certain cold regions with great temperature fluctuation.

As for the relative humidity inside tents, J\&P tent users seemed to have the most serious problem. Nearly half of them $(42 \%)$ said it was too dry, as opposed to $15 \%$ of S\&A tent users and $10 \%$ of D\&N tent users. The extremely cold and dry air in the polar regions contributed to this problem. The humidity problem was compounded by using electrical heating systems inside tents. In that regard, artificial humidification inside large, heated tents may be needed. The low humidity, however, apparently helped alleviate problems related to indoor moisture build-up. About $15 \%$ of S\&A, $23 \%$ of D\&N, and $20 \%$ of J\&P tent users experienced problems with mois- users felt the daytime temperature was too cold, whereas about $31 \%$ of D\&N tent users felt too warm. For users of Jamesway and Polarhaven shelters, $41 \%$ of the respondents also felt daytime temperatures were too warm. Not surprisingly, as for night temperature, the percentage of 


\section{$\underline{\text { S\&A tent users }}$}

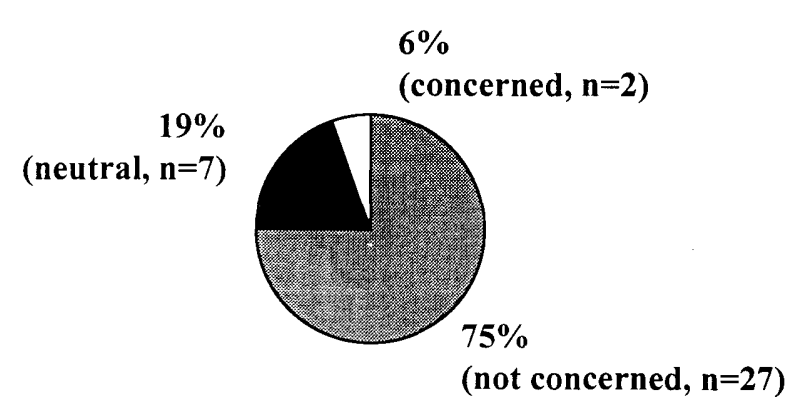

$\underline{\text { D\&N tent users }}$

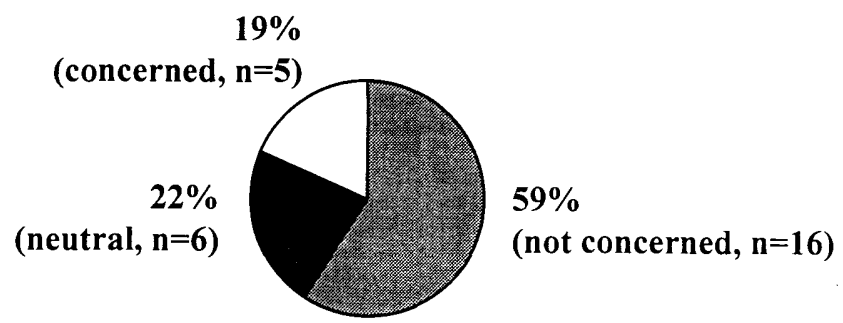

$\underline{\text { J\&P tent users }}$

$22 \%$

(neutral, $n=4$ )

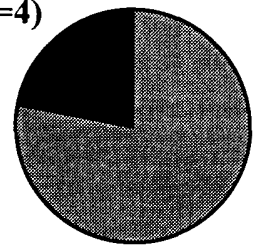

$78 \%$

( not concerned, $n=17$ )

Fig. 2. Concern about weather safety during severe weather. Question: 'Please indicate how much you agree with the statement that you were concerned about your safety during severe weather. Options: $1=$ strongly disagree, 2 , $3,4,5=$ strongly agree.'

ture build-up inside tents. This was largely true even among those who did extensive cooking inside tents. According to these data, about $72 \%$ of the users who cooked almost daily in their tents did not feel that moisture generated in cooking was a problem.

Evaluation of the indoor air quality had a similar pattern to that of the humidity. Users of S\&A and D\&N tents gave better average ratings than those of J\&P tents. About $25 \%$ of $J \& P$ tent users gave it a negative rating, as opposed to $7 \%$ of S\&A and $10 \%$ of D\&N tent users.

Evaluation of noise conditions inside tents also revealed some problems with all types of tents studied. Noise was rated poorly, with a mean score of 2.2 by $S \& A$

\section{$\underline{\text { S\&A tent users }}$}

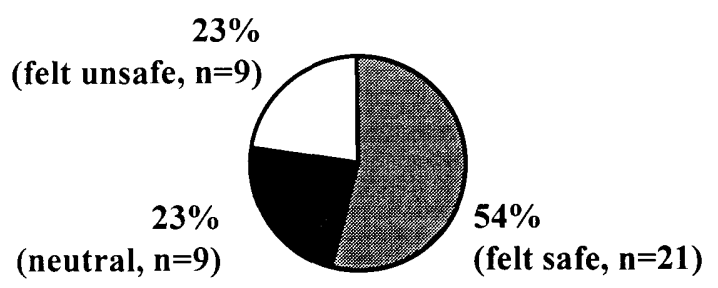

D\&N tent users

$43 \%$

(felt unsafe, $n=13$ )

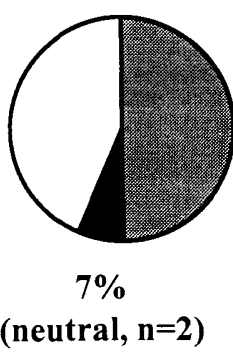

$\mathbf{5 0 \%}$

(felt safe, $n=15$ )

\section{$\underline{\text { J\&P tent users }}$}

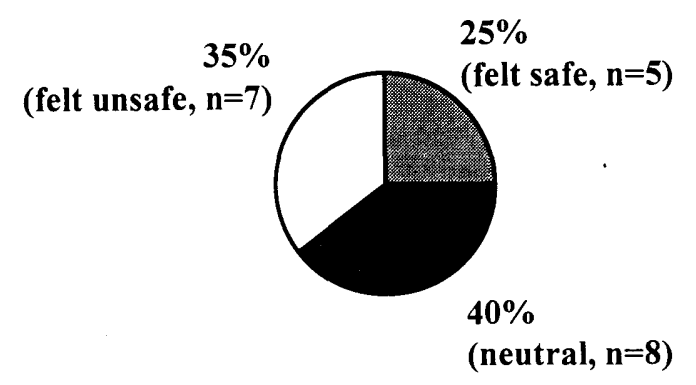

Fig. 3. Perception of fire safety of the tent. Question: 'Please indicate how much you agree with the statement that you felt the shelter was safe from fire. Options: $1=$ strongly disagree, 2, 3, 4, 5 = strongly agree.'

tent users, 1.7 by J\&P users, and 1.8 by D\&N tent users (on a five-point scale with one being the most negative and five the most positive). Noise coming from wind and slapping tent materials during windy days was one of the sources mentioned by a great number of the respondents. 'It made enough noise to interrupt my sleep' and 'It was too loud, like thunder or a hurricane passing by' were examples. For $\mathrm{J} \& \mathrm{P}$ tent users, the problem of wind was compounded by human noise due to multiple occupancy in the tent shelters. This was why the Jamesway and Polarhaven tents were the most problematic with regard to noise conditions.

\section{Performance of tent structures}

The fabric density of tents was found to contribute to a certain level of dissatisfaction and to problems with regard to light, moisture, and cold-air blockage (Table 3). About 


\author{
Among those who cooked \\ inside tents almost daily
}

$50 \%$

(concerned, $\mathbf{n}=17$ )

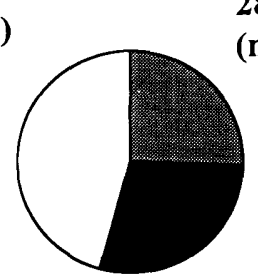

$28 \%$

(not concerned, $n=6$ )
$32 \%$

(neutral, $\mathbf{n}=11$ )
Among those who used heating inside tents almost daily

Fig. 4. Concern about fire safety among those who cooked and used heating inside tents. Question (left chart): 'How much were you concerned about fire safety due to cooking? Options: $1=$ not at all, 2, 3, $45=$ a great deal.' Question (right chart): 'How much were you concerned about fire safety of the heating system? Options: $1=$ not at all, 2, 3, 4, 5= a great deal.'

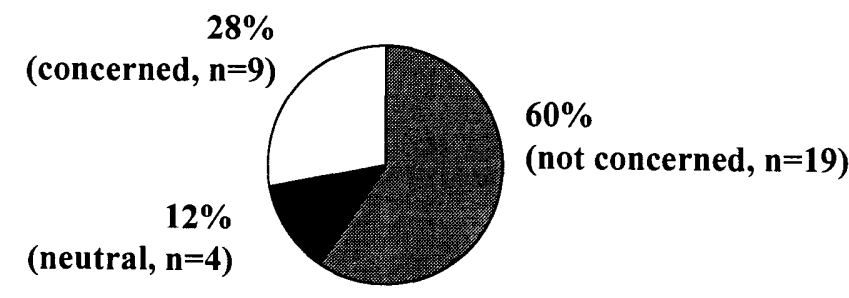

Fig. 5. Concern about oxygen depletion among those who cooked inside tents almost daily. Question: 'How much were you concerned about oxygen depletion due to cooking? Options: $1=$ not at all, 2, 3, 4, 5 = a great deal.'

$67 \%$ of $S \& A$ tent users and $75 \%$ of D\&N tent users felt that the fabric density was insufficient to block the passage of light; about $17 \%$ of S\&A tent users, $21 \%$ of D\&N tent users, and $24 \%$ of J\&P tent users felt that the fabric density was insufficient to block the passage of moisture; and slightly more than one-fourth of D\&N tent users $(29 \%)$ and of J\&P tent users (26\%) said that fabric density was somewhat insufficient to block cold air. This was significantly higher than the S\&A tent users $(10 \%)$ who felt the same.

As most of the polar and sub-polar regions have an extreme light-dark cycle, the ability of tent materials to block light is of vital importance to sleeping. A large number of respondents reported their sleeping problems were due to the insufficiency of tent fabrics in preventing bright light from entering into the tents. However, one should be cautioned that light blockage via tent materials may cause another indoor lighting problem. Many mentioned that a dark interior often made it practically impossible even to find flashlights, let alone do other things. Some respondents also mentioned that maintaining a certain level of light inside the shelters made it possible for carrying out other activities, such as reading and writing letters, instead of just sleeping. This suggests that the portable tents have to be dark inside on one hand for sleeping, and have some light on the other hand for people to see. Obviously, tent materials alone may not be the solution to meet the conflicting needs. Appropriate design of doors and windows may provide necessary alternatives.

While there were a number of different colors used for tent exteriors and interiors, responses to this study tended to suggest a variation in preference of tent colors. For instance, yellow seemed to be more desirable for the exterior, while white and yellow colors were rated favorably for the interior. Exterior and interior colors of tents also seemed to be a factor affecting overall evaluations of tents. For S\&A tent users, while their overall satisfaction with the tent was somewhat related to exterior and interior materials of tents ( $R=0.41$ and $R=0.34$, respectively), it was not related to colors of the exterior and interior $(R=0.19)$. However, for D\&N tent shelters, the overall satisfaction was closely related to both exterior and interior colors ( $R=0.44$ and $R=0.41$, respectively) and tent materials ( $R$ $=0.42$ and $R=0.48$, respectively). For J\&P tent users, overall satisfaction with the tent was also highly related to its interior and exterior colors $(\mathrm{R}=0.73$ and $\mathrm{R}=0.54$, respectively).

Providing certain means of personalization inside tents seemed to be of great importance to the users. Slightly more than half $(52 \%)$ of the respondents did some sort of personalization. It was also found that being able to personalize the space was fairly closely related to the overall satisfaction with the tents (Tau-b $=0.41, p<0.00)$. Some used pockets on interior sides of tents, while others added cots and small shelves for storage and ropes to hang wet socks or to suspend reading lights. Still others used boxes to make tables, or used dividers when shared by two.

Several other design and use-related aspects of the tents were also studied (Table 4). Regarding the size of tents, while it was not surprising to find out that both the $\mathrm{S} \& \mathrm{~A}$ and $\mathrm{D} \& \mathrm{~N}$ tents were rated considerably poorer than $J \& P$ tents, it is worth noting that $S \& A$ tents were rated relatively better than D\&N ones. About $29 \%$ of $D \& N$ tent users had negative evaluations with regard to their size, as opposed to 17\% of S\&A tent users. As for evaluations of tent space for doing some work or for leisure, about $53 \%$ of S\&A tent users and $80 \%$ of D\&N tent users said the space was not enough for doing any work. While the small tents are designed mainly for sleeping purposes, many individuals apparently had to do certain work inside tents, such as transcribing field notes, sorting field data, or fixing 
Table 2. Percentage distributions of evaluation of indoor environmental quality.

\begin{tabular}{|c|c|c|c|c|c|c|}
\hline \multicolumn{7}{|c|}{ Day temperature inside tents was $(1=$ too cold, $5=$ too warm $) ?$} \\
\hline & (1) & $(2)$ & (3) & (4) & $(5)$ & \\
\hline S\&A tents & 2.9 & 13.2 & 68.4 & 5.3 & 5.3 & $100 \%$ \\
\hline D\&N tents & 3.4 & 6.9 & 58.6 & 27.6 & 3.4 & $100 \%$ \\
\hline J\&P tents & - & 23.5 & 35.3 & 23.5 & 17.6 & $100 \%$ \\
\hline \multicolumn{7}{|c|}{ Night temperature inside tents was $(1=$ too cold, $5=$ too warm $) ?$} \\
\hline & (1) & (2) & (3) & (4) & (5) & \\
\hline S\&A tents & 7.9 & 13.2 & 71.1 & 7.9 & - & $100 \%$ \\
\hline D\&N tents & 3.6 & 25.0 & 60.7 & 7.1 & 3.6 & $100 \%$ \\
\hline J\&P tents & - & 27.8 & 55.6 & 5.6 & 11.1 & $100 \%$ \\
\hline \multicolumn{7}{|c|}{ Humidity inside tents was $(1=$ too dry, $5=$ too humid $) ?$} \\
\hline & $(1)$ & (2) & (3) & (4) & (5) & \\
\hline S\&A tents & 2.5 & 12.5 & 80.0 & 2.5 & 2.5 & $100 \%$ \\
\hline D\&N tents & 10.0 & - & 73.3 & 13.3 & 3.3 & $100 \%$ \\
\hline J\&P tents & 26.3 & 15.8 & 42.1 & 10.5 & 5.3 & $100 \%$ \\
\hline \multicolumn{7}{|c|}{ Moisture build-up inside tents was $(1=$ too much, $5=$ not a problem $) ?$} \\
\hline & $(1)$ & $(2)$ & (3) & (4) & $(5)$ & \\
\hline S\&A tents & 2.4 & 12.2 & 14.6 & 29.3 & 41.5 & $100 \%$ \\
\hline D\&N tents & 6.5 & 16.1 & 12.9 & 25.8 & 38.7 & $100 \%$ \\
\hline J\&P tents & 10.0 & 10.0 & 35.0 & 15.0 & 30.0 & $100 \%$ \\
\hline \multicolumn{7}{|c|}{ Air quality inside tents was $(1=$ always stuffy, $5=$ very good $) ?$} \\
\hline & (1) & $(2)$ & (3) & (4) & (5) & \\
\hline S\&A & - & 7.3 & 19.5 & 34.1 & 39.0 & $100 \%$ \\
\hline D\&N tents & - & 10.0 & 26.7 & 30.0 & 33.3 & $100 \%$ \\
\hline J\&P tents & 5.0 & 20.0 & 30.0 & 40.0 & 5.0 & $100 \%$ \\
\hline \multicolumn{7}{|c|}{ Noise insulation inside tents was $(1=$ poor, $5=$ excellent $) ?$} \\
\hline & $(1)$ & (2) & (3) & $(4)$ & (5) & \\
\hline S\&A tents & 35.9 & 20.5 & 33.3 & 10.3 & - & $100 \%$ \\
\hline D\&N tents & 65.5 & 6.9 & 17.2 & 6.9 & 3.4 & $100 \%$ \\
\hline J\&P tents & 50.0 & 35.0 & 15.0 & - & - & $100 \%$ \\
\hline
\end{tabular}

to $17 \%$ of $\mathrm{D} \& \mathrm{~N}$ tent users.

Results of this study also confirm advantages of a doublelayer tent-wall system. Approximately $82 \%$ of the respondents said they preferred the doublelayer tents. The advantages of the two-layer system included those such as 'better insulation for warmth; good balance between insulation and weight; outer layer cuts wind and inner one allows condensation to go through; better sound insulation; inner layer being frost liner,' as mentioned by respondents. However, information gathered in this study also pointed out some design and use problems. The two-layer walls made getting in and out cumbersome; no floor between entrances on the exterior and interior layer created some inconvenience; and snow often got blown in-between the two layers.

The data also suggest problems with the current design of tent doors. About $25 \%$ of S\&A tent users, $40 \%$ of $\mathrm{D} \& \mathrm{~N}$ tent users, and $30 \%$ of J \&P tent users instruments and equipment. For them, size of the tents was a problem. The same was true for conducting some afterwork leisure activities: about $35 \%$ of S\&A tent users and $62 \%$ of D\&N tent users felt the space was not enough. Once again, the S\&A tents were evaluated better than $\mathrm{D} \& \mathrm{~N}$ tents. As the ability to conduct certain leisure activities inside the tents is important to the well-being of people, especially during bad weather (Carrere and Evans 1994), this finding is worth noting. Evaluation of tent height revealed that a relatively larger percentage $(26 \%)$ of users of D\&N tents felt the height was too low as compared to that of S\&A tent users (12\%).

One of the tent design issues that warranted further improvement is related to the ease of set-up. Users of S\&A tents gave far better evaluations regarding this than did those using D\&N tents (Table 4). For instance, only about $14 \%$ of S\&A tent users said setting-up was difficult, as opposed to $31 \%$ of D\&N tent users. The evaluation was similar for both groups regarding taking down the tents. About $22 \%$ of S\&A tent users and $17 \%$ of D\&N tent users felt it was difficult to take down the tents.

While S\&A tents were evaluated better than D\&N tents when considering setting-up, they had a much poorer rating regarding transportability. The Scott tents are mentioned by respondents of this study as 'bulky, heavy, and difficult to transport' and 'especially in the case when they retain some moisture and freeze.' About $47 \%$ of S\&A tent users felt it was difficult to transport them, as opposed experienced at least once having difficulty opening the entrance. Some problems were caused by snow accumulation and drifts, while others were due to frozen canvas, broken zippers, and darkness inside the tent.

As the floor system of tents is one of the most important design and use issues, this study investigated three common floor systems of small tents: non-detachable floors from tent walls, detachable floors, and insulated floors. The data indicate that the non-detachable floor system was evaluated negatively by about $13 \%$ of users, and the detachable by $22 \%$ of users. An interesting finding is related to using insulation material under floors. While all of the users who used insulation materials gave positive evaluations of using the insulation materials, more than half of the others $(52 \%)$ who did not use any kind of insulation materials said they did not care about having it. Only $22 \%$ of the respondents did not use it but wished to. Plywood and foam pads were most commonly used as floor insulation. Some appreciated the design of the plywood floor insulation, which could become a crate when transporting.

\section{Psychological well-being}

As many polar researchers and support personnel have to rely on the field tents for quite a long period of time, it is necessary that the design and use of the tents also assure psychological well-being of their occupants.

A lack of privacy was a problem experienced by users 
Table 3. Percentage distributions of evaluation of tent-fabric density.

\begin{tabular}{|c|c|c|c|c|c|c|}
\hline \multicolumn{7}{|c|}{ Sufficient to block the passage of light? $(1=$ not at all, $5=$ very well $)$} \\
\hline & (1) & (2) & (3) & (4) & (5) & \\
\hline S\&A tents & 21.4 & 45.2 & 19.0 & 2.4 & 11.9 & $100 \%$ \\
\hline $\mathrm{D} \& \mathrm{~N}$ tents & 42.9 & 32.1 & 14.3 & - & 10.7 & $100 \%$ \\
\hline J\&P tents & 5.3 & 15.8 & 15.8 & 10.5 & 52.6 & $100 \%$ \\
\hline \multicolumn{7}{|c|}{ Sufficient to block the passage of moisture? $(1=$ not at all, $5=$ very well) } \\
\hline & $(1)$ & $(2)$ & $(3)$ & (4) & (5) & \\
\hline S\&A tents & 3.4 & 13.8 & 24.1 & 41.4 & 17.2 & $100 \%$ \\
\hline D\&N tents & - & 21.1 & 10.5 & 31.6 & 36.8 & $100 \%$ \\
\hline J\&P tents & 11.8 & 11.8 & 23.5 & 23.5 & 29.4 & $100 \%$ \\
\hline \multicolumn{7}{|c|}{ Sufficient to block the passage of cold air? $(1=$ not at all, $5=$ very well) } \\
\hline & (1) & (2) & (3) & (4) & (5) & \\
\hline S\&A tents & 2.4 & 7.3 & 9.8 & 46.3 & 34.1 & $100 \%$ \\
\hline$D \& N$ tents & 3.6 & 25.0 & 32.1 & 32.1 & 7.1 & $100 \%$ \\
\hline J\&P tents & - & 26.3 & 21.1 & 10.5 & 42.1 & $100 \%$ \\
\hline
\end{tabular}

\section{Conclusion and limitations}

Harsh physical environmental and social conditions in polar and sub-polar regions present great challenges to human beings living and working there, especially to those who spend an extended period of time in remote field camps of portable tents. While high task motivation helped them adapt to the harsh conditions with few complaints, this study has revealed a number of issues related to the impact of the harsh environment on human beings with regard to of all types of tents, although the magnitude of the problem varied quite significantly. J\&P tents were rated negatively in terms of privacy by $85 \%$ of their users, as opposed to $23 \%$ of S\&A tent users and $33 \%$ of users of D\&N tents. Not surprisingly, the problem of a lack of privacy was closely related to the number of people who shared the tents $(\mathrm{R}=0.56)$. The lack of privacy for Jamesway and Polarhaven tent users apparently remains a problem even though many J\&P tents have used interior partitions since 1988. The issue of privacy was viewed as important and essential to the well-being of people in a field camp, as indicated by quantitative data and written comments of the respondents.

It was also revealed that J\&P tent users apparently had much greater problems with sleeping inside tents than the other two groups. About 20\% of J\&P users said they frequently had trouble getting to sleep, as opposed to $4.8 \%$ of S\&A tent users and $10 \%$ of D\&N users. Further analysis indicated that the sleeping problem was related in part to feelings of loneliness and depression among the respondents. It was also attributable to a number of design and environmental factors, such as noise, humidity, a concern for fire safety, and night temperature.

The results of this study indicate that, among the users of S\&A tents, the feeling of depression was related to a feeling of loneliness $(R=0.72)$, problems with sleeping $(R$ $=0.48)$, and concerns about weather and fire safety $(\mathrm{R}=$ 0.28 and $R=0.23$, respectively). For $D \& N$ tent users, the feeling of depression was highly related to a feeling of loneliness $(R=0.74)$ and problems with sleeping $(R=$ 0.51 ). For $\mathrm{J} \& \mathrm{P}$ tent users, it was related to a feeling of loneliness $(R=0.66)$, a concern about fire safety $(R=$ $0.21)$, and a concern about weather safety $(R=0.23)$.

Many users felt that their moods were adversely affected when they were confined in tents due to severe weather conditions. For example, about $39 \%$ of users of S\&A tents reported a change in their mood, while only $25 \%$ of J\&P users had the same feeling. The difference might have been attributable to having some people together in tent shelters, which tended to help alleviate negative mood changes, as in the case of J\&P tent users. safety, health, and a sense of well-being. Many of those issues have clear implications for design and use of tent shelters. That problem areas varied between types of tent shelters makes these findings more worth noting.

Preliminary analysis indicates that safety is an issue of concern for a considerable percentage of users of field tent shelters. Some of the safety concerns were attributable to harsh weather, while more seemed to be related to perception of fire. The level of the concern about fire safety was significantly increased when using auxiliary heating systems and cooking inside tent shelters. A concern and a fear for fire safety will inevitably have an adverse effect on the inhabitants' psychological well-being.

Recognizing the vital importance of the tent shelter as a major piece of the built environment to protect lives and provide healthy, inhabitable conditions, this study examined several aspects of environmental quality. Some issues surfaced in the areas of day and night temperatures, humidity, noise conditions, air quality, and oxygen depletion inside tents, where people experienced problems at various levels. While these problems seem to be inevitable under extreme polar climatic conditions, the magnitude of their negative effect on users' well-being can be modified and reduced through improved design and use of the tent shelters. Appropriate design of the tent in terms of its fabric density, operable windows, floor systems, insulation materials, colors, height, and availability of interior pockets, as well as set-up and transporting, should help to alleviate the problems. It will also be necessary to consider great variations in climatic and weather conditions within polar and sub-polar regions when outfitting the tent users. Some of the problems related to interior environmental quality were apparently caused by inappropriate deployment of tents.

The data also indicate that some respondents did experience certain negative symptoms, such as depression, loneliness, and sleeping problems. The problems seemed to be attributable to factors such as fabric colors, space restrictions, tent stability, temperature control, lack of privacy, fire and weather safety, and a lack of means for personalizing space.

Based on the findings of this study, it becomes clear to 
Table 4. Percentage distributions of evaluation of selected tent functional aspects.

\begin{tabular}{|c|c|c|c|c|c|c|}
\hline \multicolumn{7}{|c|}{ Tent size was $(1=$ too small, $5=$ too large $) ?$} \\
\hline & $(1)$ & (2) & (3) & (4) & (5) & \\
\hline S\&A tents & 4.9 & 12.2 & 61.0 & 19.5 & 2.4 & $100 \%$ \\
\hline $\mathrm{D} \& \mathrm{~N}$ tents & 12.9 & 16.1 & 45.2 & 19.4 & 6.5 & $100 \%$ \\
\hline J\&P tents & 10.2 & 5.0 & 75.0 & 10.0 & - & $100 \%$ \\
\hline \multicolumn{7}{|c|}{ Tent height was $(1=$ too low, $5=$ too tall $) ?$} \\
\hline & (1) & $(2)$ & (3) & (4) & (5) & \\
\hline S\&A tents & 2.4 & 9.8 & 63.4 & 22.0 & 2.4 & $100 \%$ \\
\hline$D \& N$ tents & 12.9 & 12.9 & 58.1 & 12.9 & 3.2 & $100 \%$ \\
\hline J\&P tents & 5.0 & 5.0 & 85.0 & 5.0 & - & $100 \%$ \\
\hline \multicolumn{7}{|c|}{ Setting-up was ( 1 = very difficult, $5=$ very easy)? } \\
\hline & $(1)$ & $(2)$ & (3) & (4) & (5) & \\
\hline S\&A tents & - & 13.5 & 24.9 & 29.7 & 32.4 & $100 \%$ \\
\hline$D \& N$ tents & 6.9 & 24.1 & 10.3 & 34.5 & 24.1 & $100 \%$ \\
\hline J\&P tents & 18.2 & 18.2 & 45.5 & 18.2 & - & $100 \%$ \\
\hline \multicolumn{7}{|c|}{ Taking-down was ( $1=$ very difficult, $5=$ very easy)? } \\
\hline & $(1)$ & (2) & (3) & (4) & (5) & \\
\hline S\&A tents & - & 21.6 & 27.0 & 27.0 & 24.3 & $100 \%$ \\
\hline$D \& N$ tents & 3.4 & 13.8 & 13.8 & 41.4 & 27.6 & $100 \%$ \\
\hline J\&P tents & 18.2 & 9.1 & 45.5 & 27.3 & - & $100 \%$ \\
\hline \multicolumn{7}{|c|}{ Transporting was ( $1=$ very difficult, $5=$ very easy) $?$} \\
\hline & (1) & (2) & (3) & (4) & (5) & \\
\hline S\&A tents & 8.3 & 38.9 & 16.7 & 13.9 & 22.2 & $100 \%$ \\
\hline$D \& N$ tents & 13.3 & 3.3 & 10.0 & 20.0 & 53.3 & $100 \%$ \\
\hline J\&P tents & 36.4 & 18.2 & 36.4 & 9.1 & - & $100 \%$ \\
\hline
\end{tabular}

light for writing letters and doing other personal things inside the tent. Even some hooks or ropes inside the tents can be useful for hanging wet socks and clothes.

5. Height. One of the reasons that the ArcticOven tent was rated better than the Scott tent was its ceiling height and space. While they have approximately the same height, the latter has a teepee-shaped ceiling that makes standing up difficult. Being able to stand up inside was very desirable, especially when individuals were confined inside under bad weather conditions for considerable time.

6. Storage. Some written comments received suggested that individuals

the authors that the following should be highlighted for consideration as design concepts and/or criteria for tent manufacturing and outfitting in the future:

1. Training. Some of the issues revealed in this study, such as a concern about fire safety and cookingrelated oxygen depletion inside tents, may be eased when appropriate pre-trip training is provided. Conducting post-trip evaluations by tent users regarding the adequacy and effectiveness of training should also be considered important.

2. Temperature. While temperature in polar and subpolar regions is generally low, its significant variation from region to region and often dramatic fluctuation between day and night should not be overlooked. Otherwise, the temperature inside tents can become too warm when inappropriate types of tents are issued, as reported by respondents of this study.

3. Humidity and moisture build-up. For field-tent occupants who use auxiliary heating and engage in cooking extensively, humidity and moisture buildup inside tents are two issues that definitely need to be addressed. Adequate ventilation and breathable fabric for the inner layer of tent should help.

4. Personalization. Some design features that facilitate minimal personalization inside tents would be very useful. For instance, having a few transparent plastic pockets on the inner layer can make it possible for displaying family/friends' pictures. Light-weight, foldable shelves can be used for storing books, materials, and other personal items. Some canvas hooks and/or holders near the top of the tent can hold a flashlight, which can provide frequently had problems with storage of wet boots and gloves inside tents. In light of this, a suspended net or mesh near the tent ceiling can be very handy to hold wet items overnight.

7. Evaluation. Perhaps the most important suggestion is that tent manufacturers and outfitters should conduct systematic and periodic post-season evaluations of performance of field tents by their users. Problems revealed in this study and many enthusiastic comments received by the survey from the respondents highlight the need for evaluation. Input from the users can be very valuable for improving design and outfit of the field tents.

The study was limited in a number of ways. User responses based on recollection or memory tend to be less accurate than those obtained through on-site, in-time measurements. Pertinent information on users' experiences and perceptions can better be obtained directly from people while they are working in the field.

While the study had respondents from both scientists and support staff, the design of the questionnaire failed to make it possible to analyze the two groups separately. As scientists tend to be highly motivated, they might focus more on their research than on issues of tent design. Support staff, on the other hand, may be more critical of tent design, especially if it is their role to manage the equipment and be responsible for safety.

Methodologically, issues related to the psychological well-being of users, such as depression, performance, and mood changes, can benefit from a longitudinal collection of data from respondents instead of the one-time collection adopted by this survey. Many environmental behavioral 
studies report that collecting information on a periodic basis over time is not only appropriate but even necessary. The size of the survey respondent sample is not large enough to conduct comprehensive analysis and to provide conclusions of great statistical significance. Future on-site studies using large samples will help add more validity to the results.

\section{Acknowledgements}

The study would not have been possible without a grant from the College of Architecture and the Polar Ice Coring Office at the University of Nebraska-Lincoln. The authors also wish to thank the Office of the Polar Programs at the National Science Foundation for providing the study with valuable information.

\section{References}

Alexander, J.M. 1972. Arctic performance evaluation of a production model bare base personnelshelter. Washington, DC: US Air Force, Aeronautics System Division.

Antarctic Support Associates. 1991. Comparison report on portable field camp structure. Englewood, CO: Antarctic Support Associates

Brier, F.W. 1969. Polar camp improvements - structural, architectural, and utility accessories for the Jamesway shelter. Port Hueneme, CA: US Civil Engineering Laboratory.

Byrne, D., J. Barry, and D. Nelson. 1963. Relation of the revised repression-sensitization scale to measures of self-description. Psychological Reports 13: 323334

Carrere, S. 1990. Physiological and psychological patterns of acute and chronic stress during winter isolation in Antarctica. Unpublished PhD dissertation. Irvine: University of California, Irvine.

Carrere, S., and G.W. Evans. 1994. Life in an isolated and confined environment: a qualitative study of the role of the designed environment. Environment and Behavior 26 (6): 707-741.

Cravalho, M.A. 1994. The folk psychology of the winter experience in Antarctica. Antarctic Journal of the United States 29 (5): 382.

Derogatis, L., R. Lipman, K. Rickels, E. Uhlenhuth, and L. Covi. 1974. The Hopkins symptom checklist (HSCL): a self-report symptom inventory. Behavioral Science (19): 1-15.

Flanders, S.N. 1980. Cold regions testing of an air-transportable shelter. Hanover, NH: Cold Regions Research and Engineering Laboratory.

Flanders, S.N. 1982. Designing with wood for a lightweight air-transportable Arctic shelter: how materials were tested and chosen for design. In: Structural use of wood in adverse environments. New York: Van Nostrand: 385-397.

Floyd, P. 1974. The North Slope Center: how was it built? Northern Engineer 6 (3): 22-35.

Gunderson, E.K.E. 1974. Psychological studies in Antarctica: a review. In: Edholm, O.G., and E.K.E. Gunderson (editors). Polar human biology: the proceedings of the SCAR/IUPS/IUBS Symposium on Human Biology and Medicine in the Antarctic. London: William
Heinemann Medical Books: 352-361.

Harris, C. 1991. Environmental effects of human activities on King George Island, South Shetland Islands, Antarctica. Polar Record 27 (162): 193-204

Hutcheon, N.B., and G.O.P. Handegord. 1983. Building science for a cold climate. Toronto: John Wiley and Sons.

Johnson, P.R. 1970. The IAEE prefabricated hut. College, Alaska: University of Alaska, Institute of Arctic Environmental Engineering.

Ledbetter, C.B. 1976. Energy conservation in buildings. Hanover, NH: Cold Regions Research and Engineering Laboratory.

Leon, G. 1991. Individual and group-process characteristics of polar expedition teams. Environment and Behavior 23 (6): 723-748.

Mackay, C., T. Cox, G. Burrows, and T. Lazzerini. 1978. An inventory for the measurement of self-reported stress and arousal. British Journal of Social Psychology (17): 283-284.

Marans, R., and K. Spreckelmeyer, 1981. Evaluating built environments: a behavioral approach. Ann Arbor, Ml: University of Michigan Press

Mellor, M. 1969. Utilities on permanent snowfields. Hanover, $\mathrm{NH}$ : Cold Regions Research and Engineering Laboratory.

Mocellin, J.S.P., and P. Suedfeld. 1991. Voices from the ice: diaries of polar explorers. Environment and Behavior 23 (6): 704-722.

Natani, K. and J.T. Shurley. 1979. Socio-psychological aspects of a winter vigil at South Pole Station. In: Gunderson, E. (editor). Human adaptability to Antarctic conditions. Worcester, MA: Heffernan Press (Antarctic Research Series 22): 89-114.

Oakley, E.N.H. 1986. First Antarctic winter in tents: the Joint Services Expedition to Brabant Island. Journal of the Royal Naval Medical Services 72: 69-74.

Offen, J.L. 1994. Voices at the bottom of the world: community identity in McMurdo. Antarctic Journal of the United States 29 (5): 383.

Osherenko, G. 1992. Human/nature relations in the Arctic: changing perspectives. Polar Record 28 (167): 277284.

Pearson, M. 1992. Expedition huts in Antarctica: 18991917. Polar Record 28 (167): 261-276.

Preiser, W.F.E., H.Z. Rabinowitz, and E.T. White. 1988. Post occupancy evaluation. New York: Van Nostrand Reinhold Company

Richter, D.L. 1979. South Pole dome revisited. The Military Engineer January-February: 2-5.

Suedfeld, P. 1991. Polar psychology: an overview. Environment and Behavior 23 (6): 653-665.

Suedfeld, P. 1987. Extreme and unusual environments. In: Stokols, D., and I. Altman (editors). Handbook of environmental psychology. New York: John Wiley \& Sons: 863-887.

Ursin, H., and 12 others. 1991. Psychobiological studies of individuals in small, isolated groups in the Antarctic and in space analogous. Environment and Behavior 23 (6): 766-781.

The accuracy of references in the text and in this list is the responsibility of the authors, to whom queries should be addressed. 